\title{
Investigation into the Prevalence of Cryptosporidium Infection in Calves among Small-Holder Dairy and Traditional Herds in Tanzania
}

\author{
Emanuel S. Swai ${ }^{1}$ and Luuk Schoonman ${ }^{2}$ \\ ${ }^{1}$ Directorate of Veterinary Services, Veterinary Investigation Centre (VIC), P.O. Box 1068, Arusha 255, Tanzania \\ ${ }^{2}$ Department of Animal Production, Tanga Dairy Trust (TADAT), P.O. Box 1720, Tanga 255, Tanzania
}

Correspondence should be addressed to Emanuel S. Swai, esswai@gmail.com

Received 16 September 2010; Accepted 10 November 2010

Academic Editor: David W. Horohov

Copyright (c) 2010 E. S. Swai and L. Schoonman. This is an open access article distributed under the Creative Commons Attribution License, which permits unrestricted use, distribution, and reproduction in any medium, provided the original work is properly cited.

\begin{abstract}
A cross-sectional study was conducted to determine prevalence and risk factors of cryptosporidiosis in bovine from two contrasting production system in and around Tanga municipality between May 2003 and January 2004. The study populations comprised 117 calves aged $\leq 3$ months, randomly selected from 44 smallholders dairy and traditional managed herds, respectively. Individual calf and herd-level information was collected using a structured questionnaire and feacal samples were screened for Cryptosporidium spp oocysts using the modified Ziehl-Neelsen method. Overall, $35 \%$ of the calves in the study were shedding Cryptosporidium spp oocysts, with at least one positive calf detected in $54.5 \%$ of herds. Independent risk factors for cryptosporidiosis were: age $\geq 1$ to $\leq 2$ months and level of cleanness of calf house floor categorized as dirty $(P<.05)$. Similarly an increases risk of Cryptosporidium spp infection was found in calves from smallholder dairy units compared to traditional herds $(P<.05)$. The finding highlights that Cryptosporidium spp is prevalent among calves in the area under study. The high prevalence of cryptosporidiosis detected in this study suggests that it may have a significant impact on livestock industry and that the close interaction between cattle and human may play a role in zoonotic transmission to humans.
\end{abstract}

\section{Introduction}

Cryptosporidiosis is a zoonosis caused by the apicomplexan intracellular, extracytoplasmic coccidian parasite of the genus Cryptosporidium that can infect a wide range of animals, including man $[1,2]$. Cryptosporidium hominis (formerly C. parvum genotype 1) is human specific and maintained in human-to-human transmission cycles, while C. parvum (formerly C. parvum genotype 2) is maintained by a number of different animal reservoir host species including bovines [3]. C. parvum also causes disease in humans and is, therefore, a zoonosis transmitted from cattle to humans but in immunocompromised individuals such as children and patients with Acquired Immunodeficiency Syndrome (AIDS), the infection fulminates and might be life-threatening [4].

In cattle Cryptosporidium infections are transmitted by the faeco-oral route, and the disease is readily transmissible: oocysts persist for long periods in suitable environment [5], and low numbers of oocysts may produce infection in susceptible hosts [6]. Clinical illness and diarrhoea caused by Cryptosporidium spp. have been reported in several species of young animals including bovine calves as young as 4 days [7].

In Tanzania, Cryptosporidium spp. infections in human and livestock appear common [8-12]; however, systematic studies targeting young calves reared under different production system are patchy and not well documented. As a result information on disease prevalence, distribution, and impact on these future replacement stocks is inadequate and not precisely known.

This study investigated the prevalence of Cryptosporidium spp. infections amongst bovine calves in two contrasting cattle production systems of Tanga region, Tanzania. An attempt was made to investigate potential risk factors for infection in these calves that may point to methods by which 
infections may be controlled and/or transmission to humans limited.

\section{Material and Methods}

2.1. Study Area and Population. The study was conducted on both smallholder dairy herds $(\leq 10$ graded animals of all ages, breed, and sex and intensively managed) and traditional herds ( $\geq 30$ indigenous cattle of all ages and sex and extensively managed) in and around Tanga municipality. Characteristics of the study area are described in detail elsewhere [13]. The type of animals kept under smallholder units includes taurine breed (Friesian, Ayrshire, Jersey, Simmental) and crosses of these breeds with bos indicus breeds (Tanzania shorthorn Zebu, Boran, and Sahiwal). The level of taurine blood varies from 50 to $85 \%$. Traditional herds comprise mainly Tanzania shorthorn zebu (TSHZ). Only calves up to 3 months of age were sampled. Calves are known to be susceptible and suffer the severe form infections compared to other age group $[5,7]$.

2.2. Study Design and Herds Selection. This study was part of the broader cross-sectional study on zoonotic diseases and relative impact on public health conducted on the same farms between May 2003 and January 2004. During the cross-sectional study, 130 farms (105 smallholder dairies and 25 traditional herds) were selected randomly (using Epitable calculator of the Epi-info, version 6.04b) [14] from a sampling frame of 1,730 farms, comprising 12,500 animals that belonged to the Tanga dairy development programme and district livestock department databases. Recruitment of study calves was based on inclusion criteria of calves on the study farms with an age of less than three months as at 1st May 2003 through 1st January 2004. This selection criterion resulted in the recruitment of 28 smallholder dairy and 16 traditional herds comprising 117 calves. Consistent to other studies, cryptosporidiosis is considered one of the most common causes of neonatal diarrhea in cattle $[7,15]$. All calves were sampled only once (cross-sectional) during the period of May 2003 and January 2004.

2.3. Questionnaire Design and Data Collection. Information about each herd and the calves kept was collected by means of a structured questionnaire, which was completed at all the selected herds on a single visit. The questionnaire was designed to comprise mostly closed ended (categorical) questions to ease data processing, minimize variation, and improve precision of responses [16]. The questionnaire was administered using the national Swahili dialect by a veterinary department staff member, who was trained in participatory research methodologies. Important herd-, calfand area-level data recorded included calf location (urban, periurban, or rural), age determined from birth records, type of floor in the calf house (concrete, kraal/stone, wooden) as well as level of floor hygiene or cleanness subjectively assessed as highly, moderate, or mild dirty, and source of drinking water (tap, rain water, shallow well, river, pond). At the same time, information on diarrhoea and other ill health signs (coughing, dullness, ocular and nasal discharges) in calves was as well collected.

2.4. Sample Collection and Handling. During the visit to each herd, a fresh rectal faecal sample was collected from each calf into a sterile, airtight, $10 \mathrm{~mL}$ plastic tube. Collected faecal samples were labelled and transported in a coolbox to local laboratories in Tanga (at least within 6 hours of collection) prior to despatch in refrigerated containers to Sokoine University of Agriculture (SUA), Morogoro for analysis.

2.5. Laboratory Analysis of Fecal Samples. Presence of Cryptosporidium spp. oocysts in faeces samples was detected using the modified Ziehl-Neelsen staining technique as described by Clarke and McIntyre [17]. Briefly, faecal smears were prepared on a microscope slide, air dried at room temperature, and fixed with absolute alcohol (methanol) for 5 minutes. Fixed smears were stained with dilute carbol fuchsin $(1: 10)$ for $3-5$ minutes and washed with tap water. Smears were decolourised using 3\% acid alcohol (3\% HCL in ethanol) for 10-15 minutes then counterstained with $0.5 \%$ malachite green solution for one minute. Smear slides were washed with tap water, air dried, and then examined under the microscope at $\mathrm{x} 400$ magnification. Cryptosporidium spp. oocysts appear as pink to red, spherical to ovoid bodies against a green to purple background. Samples were considered positive if at least one morphologically distinct Cryptosporidium spp. oocyst was observed. Intensities of the oocysts detected based at $\mathrm{x} 400$ magnification were expressed as $1+$ ( $<5$ oocyst per slide), $2+$ ( 1 to 10 oocysts per field per view) and $3+(>10$ oocysts per field per view) [18].

2.6. Biostatistical Analysis. The data were stored using Microsoft Access and analyzed by using Epi-Info version 6.04d software (CDC, 1996) [14] statistical packages. Descriptive statistics like rate, frequency, and proportions were used. Risk factors thought to be associated with the prevalence of Cryptosporidium spp. oocyst shedding (age, location, production system, source of water, house flooring system, and level of cleanness) were evaluated using Chisquare analysis (Epi-Info version 6.04d software, CDC, 1996), with $P<.05$ as the indicative of significance level.

\section{Results}

3.1. Distribution of Risk Factors. Descriptions of herd-level and calf-level for the 117 calves sampled in the area under study are given in Table 1. Fifty seven percent of the sampled calves consisted of the indigenous breeds. Majority of the herds $(63.6 \%)$ visited were smallholders dairy managed under exclusive zero grazing. Housing flooring systems was classed as made up of stones/kraal and were often found dirty $(68 \%)$ at a time of visit. Approximately equal proportions of calves were sampled from the age category of one to two months. The mean age of the 117 calves investigated was 49 days (range 7-84 days), with $70(60 \%)$ of the calves being rural residents. None of the examined calves were diarrheic 


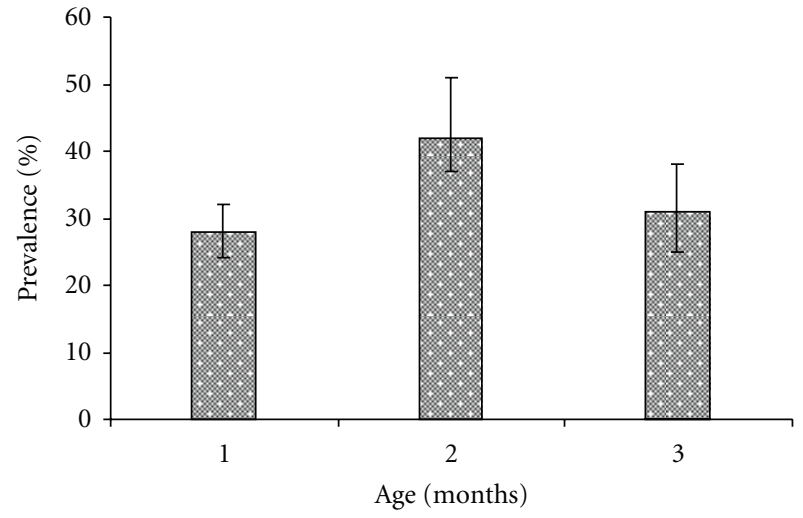

Figure 1: Age prevalence profile $( \pm 95 \% \mathrm{CI})$ of Cryptosporidium oocysts in the sampled calves in Tanga (May 2003-January 2004).

or showing any obvious ill health signs. Further details are shown in Table 1.

3.2. Estimating Cryptosporidium spp Oocysts Infection Prevalence. The overall individual calf- and herd-level cryptosporidiosis prevalence and their respective 95\% Confidence intervals [CIs] are shown in Table 2. Calves in traditional herds had a significant lower prevalence compared to calves in smallholder herds $(P<.05)$. The cryptosporidiosis prevalence profiles (with 95\% CI for the exact binomial proportions) by age category are shown in Figure 1. Calves of $\geq 1$ to $\leq 2$ months of age had a higher prevalence than younger ( $\leq 1$ month) and older calves $(\leq 3$ months $)(P<$ $.05)$. Based on oocysts detection intensities, $7.3 \%$ (4/41) of the Cryptosporidium spp positives were categorized as heavy, $9.7 \%(4 / 41)$ as moderate, and $83 \%(34 / 41)$ as mild infection.

3.3. Relationship between Variables Investigated and Cryptosporidium Oocyst Infection. One variable was significantly associated with variation in prevalence to Cryptosporidium spp infection in the univariable analysis. Calves were associated with a higher risk of exposure to Cryptosporidium spp infection if they slept/or stayed at dirty floors compared to those slept at moderate to clean floors (odd ratio [OR] $=1.82,95 \%$ CI $1.15-3.02, P=.01$ for dirty floors). At herd level, however, the type of flooring in the calf housing, either concrete or dirt flooring, did not influence the cryptosporidiosis herd prevalence. Also the water source, urban tap water as compared to water from shallow wells or surface water, was not associated with the cryptosporidiosis prevalence at herd level. None of the other investigated variables were associated with Cryptosporidium spp oocyst shedding.

\section{Discussion}

In this study, there was evidence that, in and around Tanga municipality, calves are infected by Cryptosporidium spp, indicating that bovine cryptosporidiosis is endemic and locally widespread. The overall herd-level prevalence of
TABle 1: Characteristics of the 117 selected calves in terms of animal- and herd-level variables from Tanga (May 2003-January 2004).

\begin{tabular}{|c|c|c|c|}
\hline Category & Levels & Frequency & Percentages \\
\hline \multicolumn{4}{|c|}{ Herd-level factors $(n=44)$} \\
\hline \multirow{2}{*}{$\begin{array}{l}\text { Production } \\
\text { system }\end{array}$} & Smallholders & 28 & 63.6 \\
\hline & Traditional & 16 & 36.4 \\
\hline \multirow{3}{*}{$\begin{array}{l}\text { Flooring } \\
\text { system }\end{array}$} & Concrete & 14 & 31.8 \\
\hline & Kraal/stones & 28 & 63.6 \\
\hline & Wooden & 2 & 4.5 \\
\hline \multirow{3}{*}{$\begin{array}{l}\text { Level of } \\
\text { cleanness }\end{array}$} & Very dirty & 9 & 20.4 \\
\hline & Slightly dirty & 21 & 47.7 \\
\hline & Clean & 14 & 31.8 \\
\hline \multirow{3}{*}{$\begin{array}{l}\text { Source of } \\
\text { water }\end{array}$} & Tap water & 22 & 50 \\
\hline & Shallow wells & 4 & 9.09 \\
\hline & River, pond, rain & 18 & 40.9 \\
\hline \multicolumn{4}{|c|}{ Area level factors $(n=117)$} \\
\hline \multirow{3}{*}{$\begin{array}{l}\text { Calf } \\
\text { location }\end{array}$} & Urban & 17 & 14.5 \\
\hline & Peri-urban & 30 & 25.6 \\
\hline & Rural & 70 & 59.9 \\
\hline \multicolumn{4}{|c|}{ Calf-factors $(n=117)$} \\
\hline \multirow{2}{*}{ Breed } & Cross-bred & 50 & 42.7 \\
\hline & Indigenous TSHZ & 67 & 57.3 \\
\hline \multirow{3}{*}{ Age } & $\leq 1$ month & 37 & 42.7 \\
\hline & $\geq 1$ to $\leq 2$ months & 48 & 41.02 \\
\hline & $\leq 3$ months & 32 & 27.3 \\
\hline \multirow{2}{*}{$\begin{array}{l}\text { Health } \\
\text { status }\end{array}$} & Ill signs/diarrheic & 0 & 0 \\
\hline & healthy & 117 & 100 \\
\hline
\end{tabular}

$54.5 \%$ implies the presence of the disease in majority of the herds in the study area. Regarding production systems, $63 \%$ of herds in the traditional and $50 \%$ of the herds tested in smallholder dairying system had at least one Cryptosporidium spp. oocyst shedding calf per farm. The herd-level prevalence difference observed in the two production systems was not statistically significant $(P>.05)$. This demonstrates the disease being important in both production systems. The recorded prevalence indicated, however, that certain herd-level factors, such as those involving close contact with unhygienic or dirty floor houses, were relatively high-risk in terms of Cryptosporidium spp infection. Some studies have shown that parasite oocysts are able to survive for extended periods in faeces and environment, and very low dose of viable oocysts can cause an infection [2]. The warm humid coastal environment of Tanga region may also favour the survival and spread of infective oocysts.

The detected prevalence (35\%) of infection in the calves was relatively higher than the $16.5 \%$ reported in diarrhoeic calves under 3 months of age in Morogoro, Tanzania [10], but generally lower than the prevalence observed in other studies of similar age range in Tanzania and elsewhere, for example, up to $62 \%$ [19] and $80 \%$ in calves in Britain [20]. 
TABLE 2: Cryptosporidiosis prevalence (with exact $\pm 95 \%$ confidence intervals) in calves up to 3 months of age by production system (May 2003-January 2004).

\begin{tabular}{lcccc}
\hline \multirow{2}{*}{ Production system } & \multicolumn{2}{c}{ Herd level } & \multicolumn{2}{c}{ Animal level } \\
& Number positives & Prevalence, \% $( \pm 95 \% \mathrm{CI})$ & Number positives & Prevalence, \% $( \pm 95 \%$ CI $)$ \\
\hline Traditional & 10 & $63(51.5-74.4)$ & 15 & $22.4(17.8-26.2)$ \\
Smallholder dairy & 14 & $50(40.7-59.3)$ & 26 & $52(45.1-58.9)$ \\
Overall & 24 & $54.5(45.6-60.4)$ & 41 & $35(30.9-39.1)$ \\
\hline
\end{tabular}

CI: lower and upper limits for 95 percent confidence interval of the prevalence.

The relevant data from North and East Africa, America, and from other environments similar to those found in Tanzania also indicate that bovine cryptosporidiosis is prevalent and widespread among calves populations. For example in other modified $\mathrm{ZN}$ screening-based investigations, prevalences of $86.7 \% ; 38 \% ; 18 \% ; 17.1 \%$, and $25 \%$ have been reported in Tunisia, Uganda, Kenya, Argentina, and Mexico, respectively [7, 21-24]. The apparent variability of prevalence between geographical localities and reports may reflect differences in the levels of calf management practices employed at farm level, housing-related factors (i.e., single housed calves, cleanness of the calf sleeping places), calf-related factors at a time of sampling (diarrhoeic versus nondiarrhoeic), nature of the study (cross-sectional versus prospective longitudinal studies), and fecal screening technique used [25-27].

Although modified ZN remains the widely used screening test for cryptosporidiosis, the test does have limitations [28-30]. Therefore, our prevalence estimates are likely to be at variance with the true prevalence in calves. A wider use of $\mathrm{ZN}$ under field conditions is constrained by the low sensitivity, time consuming (about 30 to 45 minutes), necessitating intensive training and experience to interpret the results. Resource constraints affecting logistics and laboratory capacity were the main reasons that prohibited utilization of tests of higher sensitivities in this study. However, consistent with the results of studies by $[9,19]$, the findings of this study indicate evidence of exposure to the Cryptosporidium spp. and suggest that there is a need for strict adherence to hygienic and good calf husbandry practice at farm level. It can also be recommended that other tests of higher sensitivities, that is, PCR, ELISA, should be employed in order to improve test sensitivity [27, 30-33].

Sex of the calf was not associated with Cryptosporidium spp. oocyst shedding in this study, and this is in agreement with the report of $[34,35]$. The prevalence rate in middle age group (43\%) showed statistically significant difference from young $(27 \%)$ and older calves $(31 \%)(P<.05)$. This finding was at variance with earlier reports $[24,36]$ where such age range was concluded to have no role in cryptosporidiosis epidemiology. Perhaps this assumption needs further investigation.

\section{Conclusion}

In conclusion, overall animal and herd prevalence was high, suggesting that cryptosporidiosis is endemic and locally widespread disease. Calves were more likely to shed Cryptosporidium spp. positive oocysts if they were raised at dirty floor houses most likely due to the increased microenvironment for Cryptosporidium spp. oocyst survival and persistency. A further study prospective in nature, capturing seasonal variations to elucidate the magnitude of the disease (mortalities and reduced production), is desirable. Moreover, studies to understand the dynamics of transmission cycles and the genetic diversity of Cryptosporidium spp. on the farms, and to identify and if possible alter management practices that are risk factors for human infections, should be initiated and undertaken.

\section{Conflict of Interests}

The authors declare that they have no competing interests.

\section{Acknowledgments}

The authors thank all the stockmen who participated and the livestock field staff for their very considerable support and assistance. Thanks are extended to the Director of Veterinary Service, Tanzania for permission to publish this paper.

\section{References}

[1] R. Fayer and B. L. P. Ungar, "Cryptosporidium spp. and cryptosporidiosis," Microbiological Reviews, vol. 50, no. 4, pp. 458-483, 1986.

[2] C. Z. Chako, J. W. Tyler, L. G. Schultz, L. Chiguma, and B. T. Beerntsen, "Cryptosporidiosis in people: it's not just about the cows," Journal of Veterinary Internal Medicine, vol. 24, no. 1, pp. 37-43, 2010.

[3] J. Plutzer and P. Karanis, "Genetic polymorphism in Cryptosporidium species: an update," Veterinary Parasitology, vol. 165, no. 3-4, pp. 187-199, 2009.

[4] E. R. Houpt, O. Y. Bushen, N. E. Sam et al., "Short report: asymptomatic Cryptosporidium hominis infection among human immundeficiency virus-infected patients in Tanzania," American Journal of Tropical Medicine and Hygiene, vol. 73, no. 3, pp. 520-522, 2005.

[5] J. A. Castro-Hermida, Y. A. González-Losada, and E. AresMazás, "Prevalence of and risk factors involved in the spread of neonatal bovine cryptosporidiosis in Galicia (NW Spain)," Veterinary Parasitology, vol. 106, no. 1, pp. 1-10, 2002.

[6] N. E. Ramirez, L. A. Ward, and S. Sreevatsan, "A review of the biology and epidemiology of cryptosporidiosis in humans and animals," Microbes and Infection, vol. 6, no. 8, pp. 773-785, 2004. 
[7] V. F. Del Coco, M. A. Córdoba, and J. A. Basualdo, "Cryptosporidium infection in calves from a rural area of Buenos Aires, Argentina," Veterinary Parasitology, vol. 158, no. 1-2, pp. 31-35, 2008.

[8] J. A. Matovelo, T. Landsverk, and G. Amaya PoSada, "Cryptosporidiosis in Tanzanian goat kids: scanning and transmission electron microscopic observations," Acta Veterinaria Scandinavica, vol. 25, no. 3, pp. 322-326, 1984.

[9] K. Esrony, D. M. Kambarage, M. M. A. Mtambo, A. P. Muhairwa, and L. J. M. Kusiluka, "Intestinal protozoan parasites of pigs reared under different management systems in Morogoro, Tanzania," Journal of Applied Animal Research, vol. 10, no. 1, pp. 25-31, 1996.

[10] M. M. A. Mtambo, J. B. Sebatwale, D. M. Kambarage et al., "Prevalence of Cryptosporidium spp. oocysts in cattle and wildlife in Morogoro region, Tanzania," Preventive Veterinary Medicine, vol. 31, no. 3-4, pp. 185-190, 1997.

[11] J. P. Cegielski, Y. R. Ortega, S. McKee et al., "Cryptosporidium Enterocytozoon, and Cyclospora infections in pediatric and adult patients with diarrhea in Tanzania," Clinical Infectious Diseases, vol. 28, no. 2, pp. 314-321, 1999.

[12] E. S. Swai, N. P. French, E. D. Karimuribo et al., "Prevalence and determinants of Cryptosporidium spp. infection in smallholder dairy cattle in Iringa and Tanga regions of Tanzania," Onderstepoort Journal of Veterinary Research, vol. 74, no. 1, pp. 23-29, 2007.

[13] L. Schoonman, Epidemiology of leptospirosis and other zoonotic diseases in cattle in Tanzania and their relative risk to public health, Ph.D. thesis, University of Reading, Reading, UK, 2007.

[14] Epi-info ${ }^{\mathrm{TM}}$, User's manual, version 6.04d, Centers for disease control, version 6.04d, Atlanta, Ga, USA and Geneva, Switzerland, pp. 6-20, 1996.

[15] K. W. Angus, "Cryptosporidiosis in ruminants," in Cryptosporidiosis of Man and Animals, J. P. Dubey, C. A. Speer, and R. Fayer, Eds., pp. 83-104, CRC Press, Boca Raton, Fla, USA, 1990.

[16] M. Thrusfield, Veterinary Epidemiology, Blackwell Science, Oxford, UK, 2000.

[17] S. C. Clarke and M. McIntyre, "Acid-fast bodies in faecal smears stained by the modified Ziehl-Neelsen technique," British Journal of Biomedical Science, vol. 58, no. 1, pp. 7-10, 2001.

[18] D. P. Casemore, "Laboratory methods for diagnosing cryptosporidiosis," Journal of Clinical Pathology, vol. 44, no. 6, pp. 445-451, 1991.

[19] B. Lema, Study of Aetiologies of neonatal calf diarrhoea in selected farms in Tanzania, Ph.D. thesis, University of Giessen, Giessen, Germany, 1990.

[20] C. A. Scott, H. V. Smith, M. M. A. Mtambo, and H. A. Gibbs, "An epidemiological study of Cryptosporidium parvum in two herds of adult beef cattle," Veterinary Parasitology, vol. 57, no. 4, pp. 277-289, 1995.

[21] R. Soltane, K. Guyot, E. Dei-Cas, and A. Ayadi, "Cryptosporidium parvum (Eucoccidiorida: Cryptosporiidae) in calves: results of a longitudinal study in a dairy FARM in Sfax, Tunisia," Parasite, vol. 14, no. 4, pp. 309-312, 2007.

[22] J. Nizeyi, M. Cranfield, and T. Graczyk, "Cattle near the Bwindi Impenetrable National Park, Uganda, as a reservoir of Cryptosporidium parvum and Giardia duodenalis for local community and free-ranging gorillas," Parasitology Research, vol. 88, no. 4, pp. 380-385, 2002.

[23] E. K. Kang'Ethe, B. McDermott, G. M. M'Ibui, T. F. Randolph, and A. K. Langat, "Investigation into the prevalence of bovine cryptosporidiosis among small-holder dairy households in
Dagoretti Division, Nairobi, Kenya," East African Medical Journal, vol. 84, supplement 11, pp. S76-S82, 2007.

[24] S. Maldonado-Camargo, E. R. Atwill, J. A. Saltijeral-Oaxaca, and L. C. Herrera-Alonso, "Prevalence of and risk factors for shedding of Cryptosporidium parvum in Holstein Freisian dairy calves in central México," Preventive Veterinary Medicine, vol. 36, no. 2, pp. 95-107, 1998.

[25] A. M. El-Shazly, A. Gabr, M. S. E. Mahmoud, S. S. A. Aziz, and W. A. Saleh, "The use of Ziehl-Neelsen stain, enzyme-linked immunosorbent assay and nested polymerase chain reaction in diagnosis of cryptosporidiosis in immunocompetent, compromised patients," Journal of the Egyptian Society of Parasitology, vol. 32, no. 1, pp. 155-166, 2002.

[26] M. Santín, J. M. Trout, L. Xiao, L. Zhou, E. Greiner, and R. Fayer, "Prevalence and age-related variation of Cryptosporidium species and genotypes in dairy calves," Veterinary Parasitology, vol. 122, no. 2, pp. 103-117, 2004.

[27] K. Kaushik, S. Khurana, A. Wanchu, and N. Malla, "Evaluation of staining techniques, antigen detection and nested PCR for the diagnosis of cryptosporidiosis in HIV seropositive and seronegative patients," Acta Tropica, vol. 107, no. 1, pp. 1-7, 2008.

[28] D. Moodley, T. F. H. G. Jackson, V. Gathiram, and J. Van den Ende, "A comparative assessment of commonly employed staining procedures for the diagnosis of cryptosporidiosis," South African Medical Journal, vol. 79, no. 6, pp. 314-317, 1991.

[29] C. Chartier, M. P. Mallereau-Pellet, R. Mancassola, and D. Nussbaum, "Détection des oocystes des Cryptosporidium dans les fecces de caprins: comparaison entre un test d'agglutination au latex et trois autres techniques conventionnelles," Veterinary Research, vol. 33, pp. 169-77, 2002.

[30] L. Potters and M. Van Esbroeck, "Negative staining technique of Heine for the detection of Cryptosporidium spp: a fast and simple screening technique," The Open Parasitology Journal, vol. 4 , pp. 1-4, 2010.

[31] M. A. Bakheit, D. Torra, L. A. Palomino et al., "Sensitive and specific detection of Cryptosporidium species in PCR-negative samples by loop-mediated isothermal DNA amplification and confirmation of generated LAMP products by sequencing," Veterinary Parasitology, vol. 158, no. 1-2, pp. 11-22, 2008.

[32] L. Xiao and Y. Feng, "Zoonotic cryptosporidiosis," FEMS Immunology and Medical Microbiology, vol. 52, no. 3, pp. 309323, 2008.

[33] M. Santín and D. S. Zarlenga, "A multiplex polymerase chain reaction assay to simultaneously distinguish Cryptosporidium species of veterinary and public health concern in cattle," Veterinary Parasitology, vol. 166, no. 1-2, pp. 32-37, 2009.

[34] J. B. Wilson, S. A. McEwen, R. C. Clarke, K. E. Leslie, D. Waltner-Toews, and C. L. Gyles, "A case-control study of selected pathogens including verocytotoxigenic Escherichia coli in calf diarrhea on an Ontario veal farm," Canadian Journal of Veterinary Research, vol. 56, no. 3, pp. 184-188, 1992.

[35] C. Silverlås, U. Emanuelson, K. de Verdier, and C. Björkman, "Prevalence and associated management factors of Cryptosporidium shedding in 50 Swedish dairy herds," Preventive Veterinary Medicine, vol. 90, no. 3-4, pp. 242-253, 2009.

[36] S. Gow and C. Waldner, "An examination of the prevalence of and risk factors for shedding of Cryptosporidium spp. and Giardia spp. in cows and calves from western Canadian cowcalf herds," Veterinary Parasitology, vol. 137, no. 1-2, pp. 50-61, 2006. 

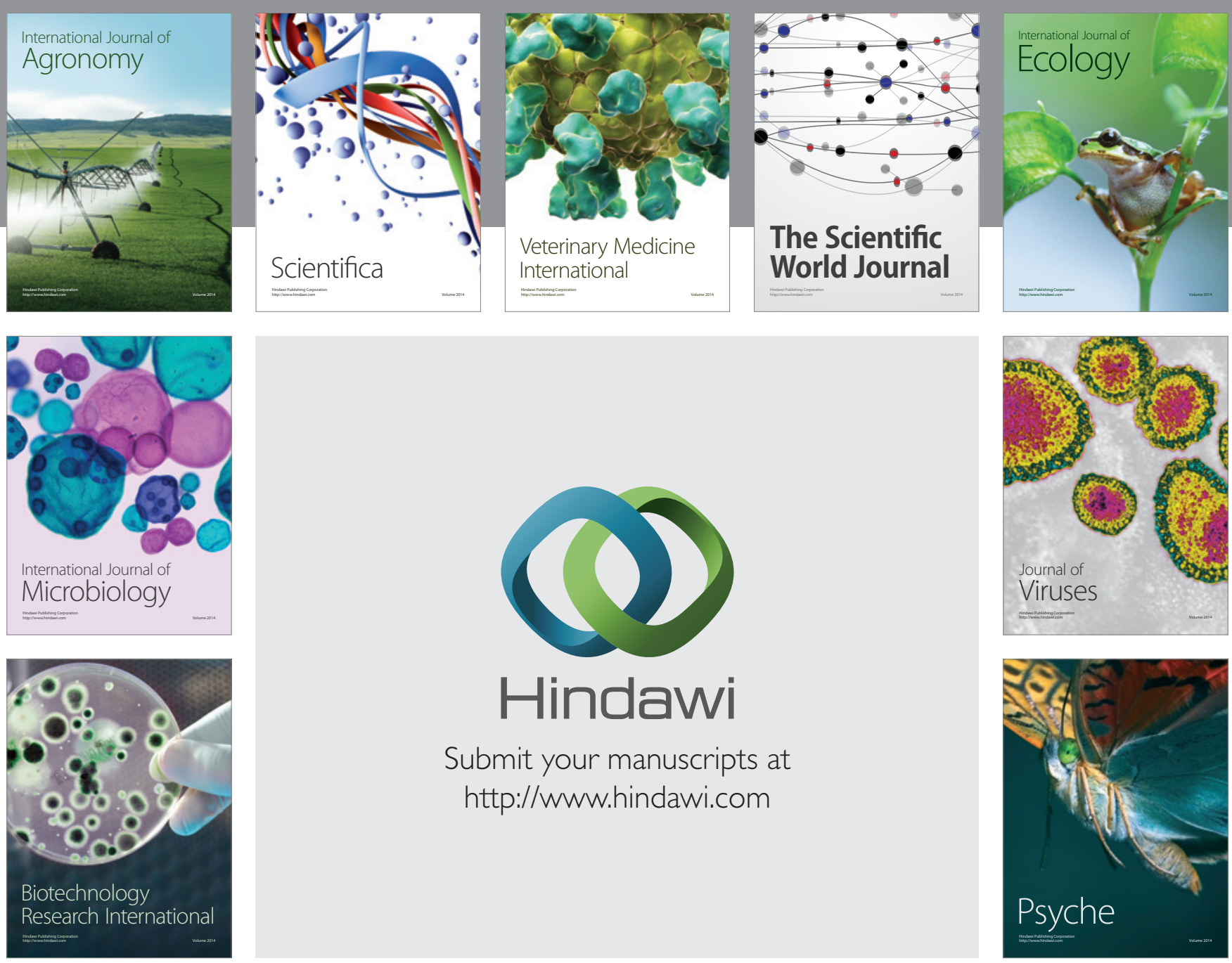

Submit your manuscripts at

http://www.hindawi.com
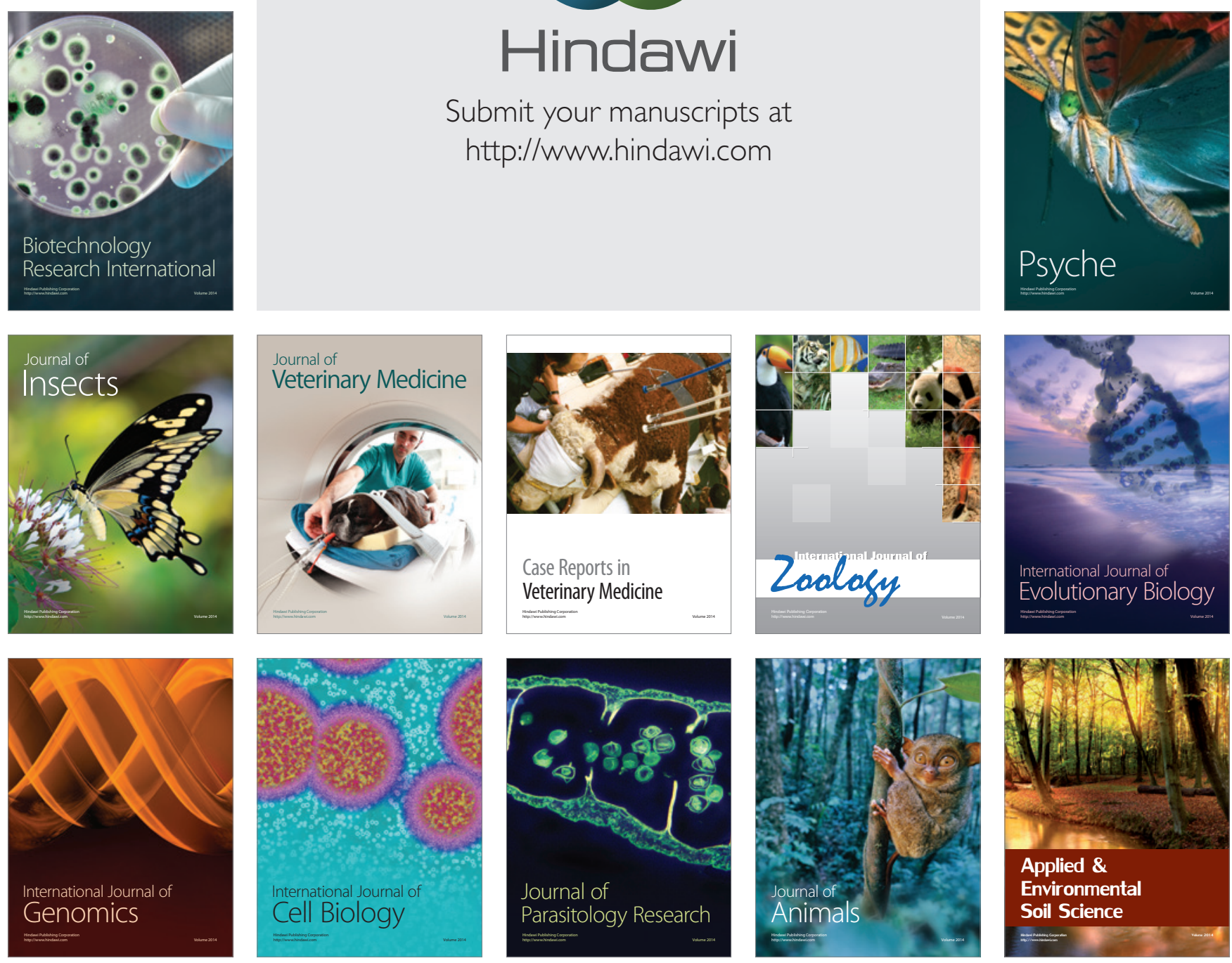